\title{
Estimation of genetic parameters for predicted nitrogen use efficiency and losses in early lactation of Holstein cows
}

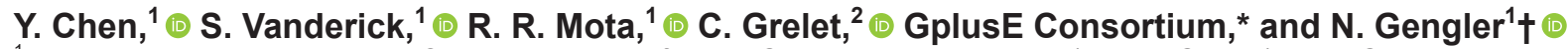 \\ ${ }^{1}$ TERRA Teaching and Research Center, University of Liège, Gembloux Agro-Bio Tech (ULiège-GxABT), 5030 Gembloux, Belgium \\ ${ }^{2}$ Walloon Agricultural Research Center (CRA-W), 5030 Gembloux, Belgium
}

\begin{abstract}
The objective of this study was to estimate genetic parameters of predicted $\mathrm{N}$ use efficiency (PNUE) and $\mathrm{N}$ losses (PNL) as proxies of $\mathrm{N}$ use and loss for Holstein cows. Furthermore, we have assessed approximate genetic correlations between PNUE, PNL, and dairy production, health, longevity, and conformation traits. These traits are considered important in many countries and are currently evaluated by the International Bull Evaluation Service (Interbull). The values of PNUE and PNL were obtained by using the combined milk midinfrared (MIR) spectrum, parity, and milk yield-based prediction equations on test-day MIR records with days in milk (DIM) between 5 and $50 \mathrm{~d}$. After editing, the final data set comprised 46,163 records of 21,462 cows from 154 farms in 5 countries. Each trait was divided into primiparous and multiparous (including second to fifth parity) groups. Genetic parameters and breeding values were estimated by using a multitrait (2-trait,
\end{abstract}

\footnotetext{
Received May 6, 2020.

Accepted November 5, 2020.

*List of authors within the GplusE consortium: Mark Crowe, Alan Fahey, Fiona Carter, Elizabeth Matthews, Andreia Santoro, Colin Byrne, Pauline Rudd, Roisin O'Flaherty, Sinead Hallinan, Claire Wathes, Mazdak Salavati, Zhangrui Cheng, Ali Fouladi, Geoff Pollott, Dirk Werling, Beatriz Sanz Bernardo, Conrad Ferris, Alistair Wylie, Matt Bell, Mieke Vaneetvelde, Kristof Hermans, Miel Hostens, Geert Opsomer, Sander Moerman, Jenne De Koster, Hannes Bogaert, Jan Vandepitte, Leila Vandevelde, Bonny Vanranst, Klaus Ingvartsen, Martin Tang Sorensen, Johanna Hoglund, Susanne Dahl, Soren Ostergaard, Janne Rothmann, Mogens Krogh, Else Meyer, Leslie Foldager, Charlotte Gaillard, Jehan Ettema, Tine Rousing, Torben Larsen, Victor H. Silva de Oliveira, Cinzia Marchitelli, Federica Signorelli, Francesco Napolitano, Bianca Moioli, Alessandra Crisà, Luca Buttazzoni, Jennifer McClure, Daragh Matthews, Francis Kearney, Andrew Cromie, Matt McClure, Shujun Zhang, Xing Chen, Huanchun Chen, Junlong Zhao, Liguo Yang, Guohua Hua, Chen Tan, Guiqiang Wang, Michel Bonneau, Marlène Sciarretta, Armin Pearn, Arnold Evertson, Linda Kosten, Anders Fogh, Thomas Andersen, Matthew Lucy, Chris Elsik, Gavin Conant, Jerry Taylor, Deborah Triant, Nicolas Gengler, Michel Georges, Frederic Colinet, Marilou Ramos Pamplona, Hedi Hammami, Catherine Bastin, Haruko Takeda, Aurelie Laine, Anne-Sophie Van Laere, Rodrigo Mota, Saeid Naderi Darbagshahi, Frederic Dehareng, Clement Grelet, Amelie Vanlierde, Eric Froidmont, Frank Becker, Martin Schulze, Sergio Palma Vera. †Corresponding author: nicolas.gengler@uliege.be
}

2-parity classes) repeatability model. Herd-year-season of calving, DIM, age of calving, and parity were used as fixed effects. Random effects were defined as parity (within-parity permanent environment), nongenetic cow (across-parity permanent environment), additive genetic animal, and residual effects. The estimated heritability of PNUE and PNL in the first and later parity were $0.13,0.12,0.14$, and 0.13 , and the repeatability values were $0.49,0.40,0.55$, and 0.43 , respectively. The estimated approximate genetic correlations between PNUE and PNL were negative and high (from -0.89 to -0.53 ), whereas the phenotypic correlations were also negative but relatively low (from -0.45 to -0.11 ). At a level of reliability of more than 0.30 for all novel traits, a total of 504 bulls born after 1995 had also publishable Interbull multiple-trait across-country estimated breeding values (EBV). The approximate genetic correlations between PNUE and the other 30 traits of interest, estimated as corrected correlations between EBV of bulls, ranged from -0.46 (udder depth) to 0.47 (milk yield). Obtained results showed the complex genetic relationship between efficiency, production, and other traits: for instance, more efficient cows seem to give more milk, which is linked to deeper udders, but seem to have lower health, fertility, and longevity. Additionally, the approximate genetic correlations between PNL, lower values representing less loss of N, and the 30 other traits, were from -0.32 (angularity) to 0.57 (direct calving ease). Even if further research is needed, our results provided preliminary evidence that the PNUE and PNL traits used as proxies could be included in genetic improvement programs in Holstein cows and could help their management.

Key words: genetic correlation, heritability, indirect selection, repeatability model, mid-infrared spectrum

\section{INTRODUCTION}

The concept of efficiency of dairy cows has to be put in a holistic perspective, as efficiency might enter a tradeoff with the health status and the ability of the cow to reproduce (Figure 1). Therefore, efficiency is 
also linked to well-being, robustness, and longevity of the cows. Moreover, efficiency is not only feed efficiency (Hayes and Ageeb, 2002) but also nitrogen use efficiency (NUE), which is considered one of the most important indicators of ruminant feed utilization (Wheadon et al., 2014). The protein in the feed is the most expensive raw material, so the increase in NUE is beneficial to the interests of farmers (Cantalapiedra-Hijar et al., 2018). Nitrogen emissions from the dairy industry have been identified as important factors causing groundwater and surface water pollution, and greenhouse gas emissions (Adenuga et al., 2019). The reduction of $\mathrm{N}$ emissions would protect the environment, and we might expect that environmental losses are also linked to efficiency (Figure 1).

In this research, we studied 2 traits: NUE, defined as the ratio of grams of $\mathrm{N}$ in milk per grams of $\mathrm{N}$ intake, and nitrogen loss (NL), defined as grams of $\mathrm{N}$ intake minus grams of $\mathrm{N}$ in milk (Phuong et al., 2013; Grelet et al., 2020). It has to be noted that the concept of NL used hereafter is a simple difference between $\mathrm{N}$ intake and $\mathrm{N}$ in milk. Therefore, it does only reflect imperfectly environmental losses (Figure 1). Concerning NUE, ratio traits are not preferred in genetics because of 2 issues: a potentially problematic, non-normal, distribution of records, and the difficulty of attributing changes to the numerator (here output grams of $\mathrm{N}$ in milk) or the denominator (here input grams of $\mathrm{N}$ intake). However, we studied both traits because NUE is often preferred for management purposes. As already stated, the improvement of the utilization of $\mathrm{N}$ in cattle may have an adverse effect on their health and longevity because it affects also $\mathrm{N}$ available for body reserves, maintenance needs, and even growth for young animals (Figure 1). Therefore, we also tried to study the genetic relationships between $\mathrm{N}$ efficiency traits and other important traits such as milk yields and composition, health, longevity, and other functional traits, and conformation traits.

Literature has reported that NUE shows large variability between individuals and herds, with values between $8 \%$ and $42 \%$ (Castillo et al., 2001). This suggests potential opportunities to improve NUE under the condition of sufficient genetic variance, by genetic selection. To our knowledge, genetic parameters and the correlation between NUE and NL, and with other traits in Holstein cows, have not yet been analyzed. However, efficiency of crude protein utilization (ECPU, CP in milk divided by CP intake), as reported by Lopez-Villalobos et al. (2018), was a trait that can be considered similar to NUE (ratio of grams of $\mathrm{N}$ in milk derived from $\mathrm{CP}$ in milk and grams of $\mathrm{N}$ intake derived from $\mathrm{CP}$ intake). Alternatively, ${ }^{15} \mathrm{~N}$ has been used to study the NUE and NL of cows (Cantalapiedra-Hijar et al., 2016,

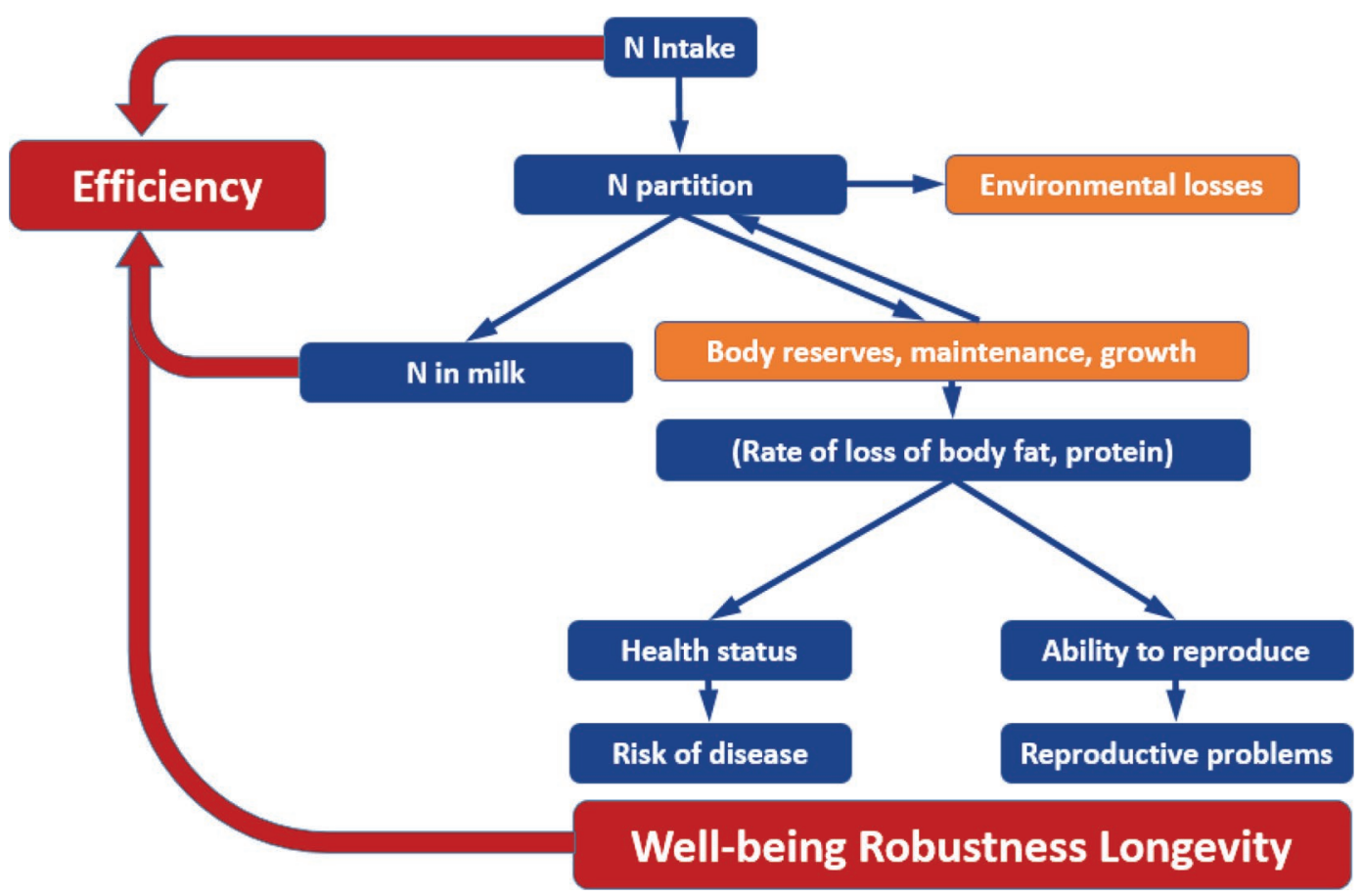

Figure 1. Holistic view of the concept of efficiency in the context of $\mathrm{N}$ (in red) and relationship between $\mathrm{N}$ in milk and $\mathrm{N}$ intake ( $\mathrm{N}$ loss shown in orange boxes) in dairy cows. (Modified from Gengler et al., 2018.) 
2018; Nasrollahi et al., 2019). Because of its high cost and complicated operation, it is impossible to collect a large amount of data needed for genetic evaluation or even genetic research. Therefore, obtaining large numbers of direct NUE and NL, as well as of ECPU records, is difficult, and the largest study, by Lopez-Villalobos et al. (2018), estimated heritability $\left(\mathbf{h}^{2}\right)$ of ECPU, using only 2,896 records. These facts highlight the urgent need for large-scale and easy-to-measure proxies for $\mathrm{N}$ (or protein) efficiency traits.

Recently, Grelet et al. (2020) established models to obtain proxies for NUE (PNUE) and NL (PNL) based on their prediction by mid-infrared (MIR) spectra. The use of spectra from the routine MIR analysis of milk is fast and simple, and allows traits to be predicted on a large scale. Predictions can be redone whenever new or better equations become available (Gengler et al., 2016). As emphasized by many recent papers (e.g., Vanlierde et al., 2015; Gengler et al., 2016), the goal of using MIR is to establish predictors that can be used as proxies for the unavailable direct traits, not the perfect replacement of a direct trait. For our traits, the correlations of 0.82 for PNUE and 0.77 for PNL observed by Grelet et al. (2020) in their validations, and defined as square root of these validation coefficients of determination $\left(\mathrm{R}^{2}\right)$, can be considered as being approximations of the level of phenotypic correlations expected between direct and our proxy traits.

The equations developed by Grelet et al. (2020) to predict PNUE and PNL were applied to a much larger data set. The objectives of this study were (1) to estimate genetic parameters of PNUE and PNL for Holstein cows in this data set and (2) to assess approximate genetic correlations between PNUE, PNL, and important traits, as milk yield and composition, health, longevity, and other functional traits, and conformation traits (30 traits).

\section{MATERIALS AND METHODS}

\section{Data Collection and Editing}

The data used in this study were collected by the Genotype Plus Environment (GplusE) FP7-Project (http://www.gpluse.eu). The initial data set, including milk MIR, parity, and milk yield, comprised a total of 52,065 records from 154 herds from 5 partner countries of the GplusE project. This specific population was also studied because the cows used in this study were genotyped during GplusE, a fact that will be important in genomic follow-up studies.

The original data were edited to select records between 5 and 50 DIM, and observed during the first 5 parities. This allow us to keep the data similar to those used for the reference population. All milk MIR spectra were standardized according to Grelet et al. (2015). The PNUE and PNL of each cow were predicted by the equations based on the models established by Grelet et al. (2020), with milk MIR spectra, milk yield, and parity as additional predictors, using support vector machine regression. The determination coefficients and root mean square errors of validation were 0.68 and $5.01 \%$ for the PNUE model, and 0.59 and $0.07 \mathrm{~kg} / \mathrm{d}$ for the PNL model, respectively.

Allowed minimum and maximum age depended on parities. For parity 1 the range was from 22 to 36 , for parity 2 from 34 to 50 , for parity 3 from 46 to 64 , for parity 4 from 58 to 78 , and for parity 5 from 70 to 92 mo of age at calving were included. Finally, the final data set contained 46,163 records of 21,462 cows from 154 farms. The distribution of the final data across 5 organizations and universities was as follows: Royal Veterinary College (London, UK; $\mathrm{n}=666$ ), Walloon Breeders Association (Ciney, Belgium; $\mathrm{n}=20,144$ ), Irish Cattle Breeding Federation Society Limited (Bandon, Ireland; $\mathrm{n}=3,543$ ), Huazhong Agricultural University (Wuhan, China; $\mathrm{n}=188$ ), and CRV (Arnhem, the Netherlands; $\mathrm{n}=21,622)$. The records were divided into 2 parity classes according to lactation numbers 1 and 2 through 5. Hereafter, these 4 traits are identified as PNUE1, PNL1, PNUE2+, and PNL2+. The pedigree related to the data sets comprised 75,700 animals.

As stated by Grelet et al. (2020), the use of MIR equations in other populations than the ones used for calibration is dangerous. Because of the lack of feeding data, we could not directly validate the predictions obtained using the equations in our population. However, by applying 2 filters, one on the MIR data and one on the values of the predictions, we acted very prudently. First, the population where the prediction equations are used should also be spectrally similar to the calibration population. A widely used strategy is to compute the global $\mathrm{H}$ parameter, which is based on the standardized Mahalanobis distance between the MIR record to be used and the calibration data sets (Whitfield et al., 1987). The global $\mathrm{H}$ is therefore a multidimensional generalized measure of how many standard deviations (SD) away a MIR record is from the mean of the corresponding calibration population. By using only spectra with a global $\mathrm{H} \leq 3$, we have limited the use of the equations to MIR records close to the calibration population, and therefore we have minimized the risk of using equations improperly. In addition, the means and SD of the values predicted for the 4 traits PNUE1, PNL1, PNUE2+, and PNL2+ were established, and records were kept only when they 
were inside a $\leq 3 \mathrm{SD}$ range. Even if these 2 measures cannot guarantee the applicability of the equations, these measures not only established that our spectra were very close to the calibration spectra but also that the predicted values stayed in a range compatible with trait definitions of Grelet et al. (2020) - that is, inside the range of the values used for calibration.

\section{Model}

A multitrait (4 traits; 2 traits, 2 parity classes) repeatability model was used for estimating variance components and breeding values. The model was fitted as follows:

$$
\mathbf{y}=\mathbf{H h}+\mathbf{X b}+\mathbf{Q q}+\mathbf{W}_{\mathbf{1}} \mathbf{c}+\mathbf{W}_{2} \mathbf{p}+\mathbf{Z a}+\mathbf{e}
$$

where $\mathbf{y}$ was the vector of 4 traits PNUE1, PNL1, PNUE2+, and PNL2+. For each trait, $\mathbf{h}$ was the vector of fixed herd-year-season of calving classes (4 seasons from December to February, March to May, June to August, and September to November); b was the vector of fixed regression coefficients for DIM, after standardization, and its quadratic; $\mathbf{q}$ was the vector of fixed regression coefficients of age of calving, after standardization, defined as a constant (parity effect), linear, and quadratic regression, defined within parities (1-5); c was a vector of nongenetic cow (acrossparity permanent environment) random effects; $\mathbf{p}$ was a vector of nongenetic cow $\times$ parity (within-parity permanent environment) random effects, modeled only for PNUE2+ and PNL2+, as they allowed us to distinguish records for the same cow occurring during different parities (second to fifth parity); a was a vector of random additive genetic effects; and $\mathbf{e}$ was a vector of random residual effects. Additionally, $\mathbf{H}, \mathbf{X}, \mathbf{Q}, \mathbf{W}_{\mathbf{1}}$, $\mathbf{W}_{2}$, and $\mathbf{Z}$ were incidence matrices assigning observations to effects.

The expected values and variances associated with this model were defined as follows:

$$
\begin{gathered}
\mathrm{E}(\mathbf{y})=\mathbf{H} \mathbf{h}+\mathbf{X} \mathbf{b}+\mathbf{Q q}, \mathrm{E}(\mathbf{c})=\mathrm{E}(\mathbf{p})= \\
\mathrm{E}(\mathbf{a})=\mathrm{E}(\mathbf{e})=\mathbf{0} .
\end{gathered}
$$

The matrices $\mathrm{V}(\mathbf{c})$ and $\mathrm{V}(\mathbf{a})$ contained blocks of $4 \times$ 4 elementary (co)variances between the 4 traits. For $\mathrm{V}(\mathbf{e})$, off-diagonals were modeled as being zero, these elements representing residual covariances between the respective traits. By this approach, environmental covariances between traits were concentrated in permanent environment effects. For $\mathrm{V}(\mathbf{p})$ the elementary (co) variance matrix was reduced to a $2 \times 2$ matrix, because only the (co)variances associated with PNUE2+ and PNL2+ were present; hereafter, we have to emphasize that this (co)variance does not exist for PNUE1 and PNL1.

\section{Variance Components, Heritabilities, and Repeatabilities}

Computations were performed using the BLUPF90 family of programs (Misztal et al., 2018). Variance components were estimated by using first the REMLF90 (version 1.84) program, and then, at convergence, approximate standard errors (SE) of all calculated parameters were obtained according to the algorithm of Meyer and Houle (2013) as implemented in the AIREMLF90 (version 1.144) program. For each trait PNUE1 and PNL1, $h^{2}$ was defined as $\sigma_{\mathrm{a}}^{2} /\left(\sigma_{\mathrm{a}}^{2}+\sigma_{\mathrm{c}}^{2}+\sigma_{\mathrm{e}}^{2}\right)$, and for PNUE2+ and PNL2+, $\mathrm{h}^{2}$ was defined as $\sigma_{\mathrm{a}}^{2} /\left(\sigma_{\mathrm{a}}^{2}+\sigma_{\mathrm{c}}^{2}+\sigma_{\mathrm{p}}^{2}+\sigma_{\mathrm{e}}^{2}\right)$, where $\sigma_{\mathrm{a}}^{2}$ was the additive genetic variance and $\sigma_{\mathrm{c}}^{2}$ was the across-parity permanent environment (nongenetic cow) variance. For PNUE2+ and PNL2+, $\sigma_{\mathrm{p}}^{2}$ was the within-parity permanent environment (nongenetic cow $\times$ parity) variance and $\sigma_{\mathrm{e}}^{2}$ was the residual variance again defined for each trait. Permanent environmental covariance between test-day records of a cow was assumed to be $\sigma_{\mathrm{c}}^{2}$ across parities and $\sigma_{\mathrm{c}}^{2}+\sigma_{\mathrm{p}}^{2}$ inside a given parity for traits PNUE2+ and PNL2+. Because traits PNUE1 and PNL1 were defined within first parity only, the associated permanent environmental covariance was limited to $\sigma_{\mathrm{c}}^{2}$. For PNUE1 and PNL1, repeatability within first parity was defined as constant parameters across the range of DIM in early lactation, as $\left(\sigma_{\mathrm{a}}^{2}+\sigma_{\mathrm{c}}^{2}\right) /\left(\sigma_{\mathrm{a}}^{2}+\sigma_{\mathrm{c}}^{2}+\sigma_{\mathrm{e}}^{2}\right)$. For PNUE2 + and PNL2+, within-parity repeatability was defined as a constant parameter across the range of DIM in early lactation, as $\left(\sigma_{\mathrm{a}}^{2}+\sigma_{\mathrm{c}}^{2}+\sigma_{\mathrm{p}}^{2}\right) /\left(\sigma_{\mathrm{a}}^{2}+\sigma_{\mathrm{c}}^{2}+\sigma_{\mathrm{p}}^{2}+\sigma_{\mathrm{e}}^{2}\right)$.

\section{Genetic, Phenotype, and Approximate Genetic Correlations}

Genetic correlations were computed directly, using the estimated genetic covariances and variances, as the ratio of the covariance to the square root of the product of the corresponding variances. Phenotype correlations were computed similarly. Required phenotypic 
A

Distribution of PNUE1 ( $n=16456$ )
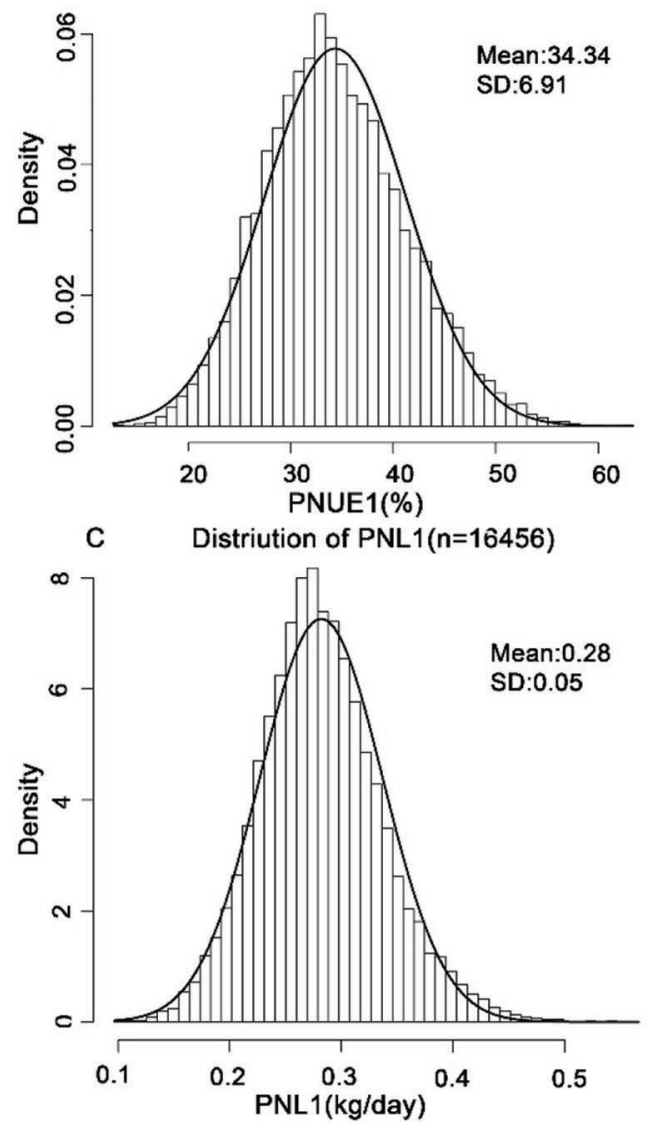

B Distribution of PNUE2+(n=29707)
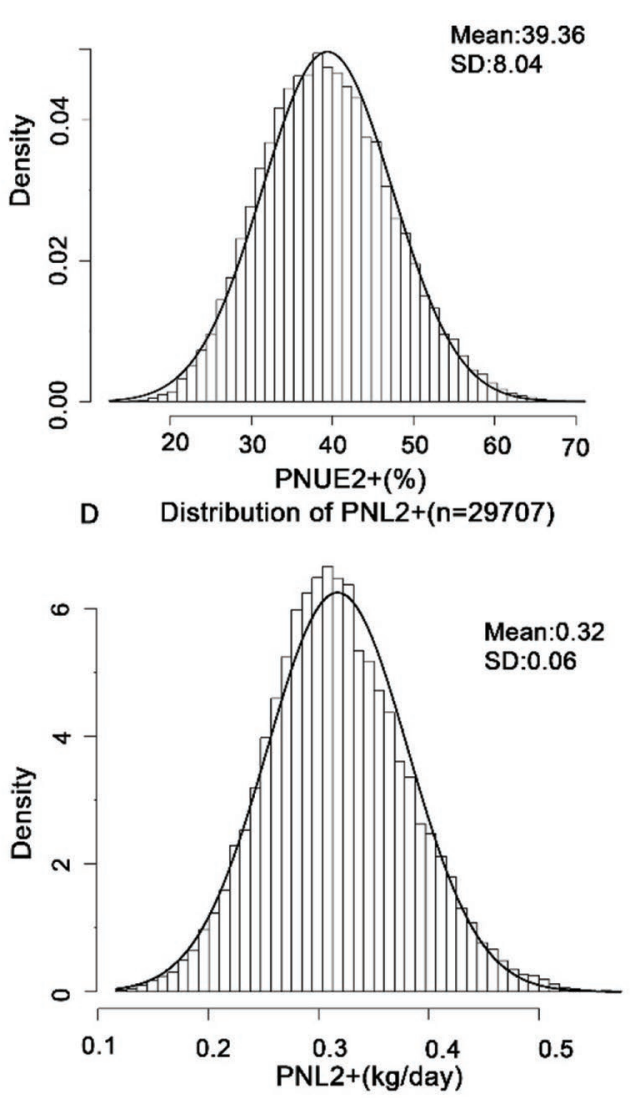

Figure 2. Distribution of predicted $\mathrm{N}$ use efficiency (A and B) and predicted $\mathrm{N}$ losses $(\mathrm{C}$ and $\mathrm{D})$ of Holstein cows. PNUE1 = predicted N use efficiency in first-parity Holstein cows; PNL1 = predicted N losses in first-parity Holstein cows; PNUE2+ = predicted N use efficiency in second- to fifth-parity Holstein cows; PNL2+ = predicted N losses in second- to fifth-parity Holstein cows.

covariances and variances were obtained as the sum of relevant (co)variance components.

Breeding values were estimated by using the BLUPF90 (version 1.68) program, and reliabilities were computed from extracted diagonal elements of the inverted coefficient matrix. The approximate genetic correlations between PNUE, PNL, and other traits of interest were estimated using the strategy presented by Blanchard et al. (1983), which is a generalization of Calo's method when groups of bulls had very diverse reliability. We identified bulls born after 1995 (included) in the pedigree, having reliabilities for all 4 novel traits that were above 0.3 and having also publishable International Bull Evaluation Service (Interbull) multiple-trait across-country evaluation-based EBV on Walloon scales (https://www.elinfo.be/telechargerEN .html). Based on a suggestion by A. Legarra (INRAE, Toulouse, France, personal communication) SE of these approximate genetic correlation estimates were estimated using 1,000 bootstrapped replicates. In the bootstrap procedure, we used the number of selected bulls to sample from all selected bulls with replacement.

Additional data preparation and processing were done using R (R Core Team, 2020; version 3.6.3), data. table package (Dowle and Srinivasan, 2019; version 1.12.8), and boot package (Canty and Ripley, 2019; version 1.3-24). The graphs were made using ggplot2 package (Wickham, 2016; version 3.30).

\section{RESULTS AND DISCUSSION}

\section{Descriptive Statistics}

The distribution of PNUE and PNL are shown in Figure 2. Under visual inspection, the range of values was acceptably normally distributed. Within the same parity, variability of PNUE and PNL remained large. Mean values for multiparous cows increased $14.86 \%$ and $12.41 \%$ over the primiparous Holstein cows, respectively. As explained previously, based on ob- 


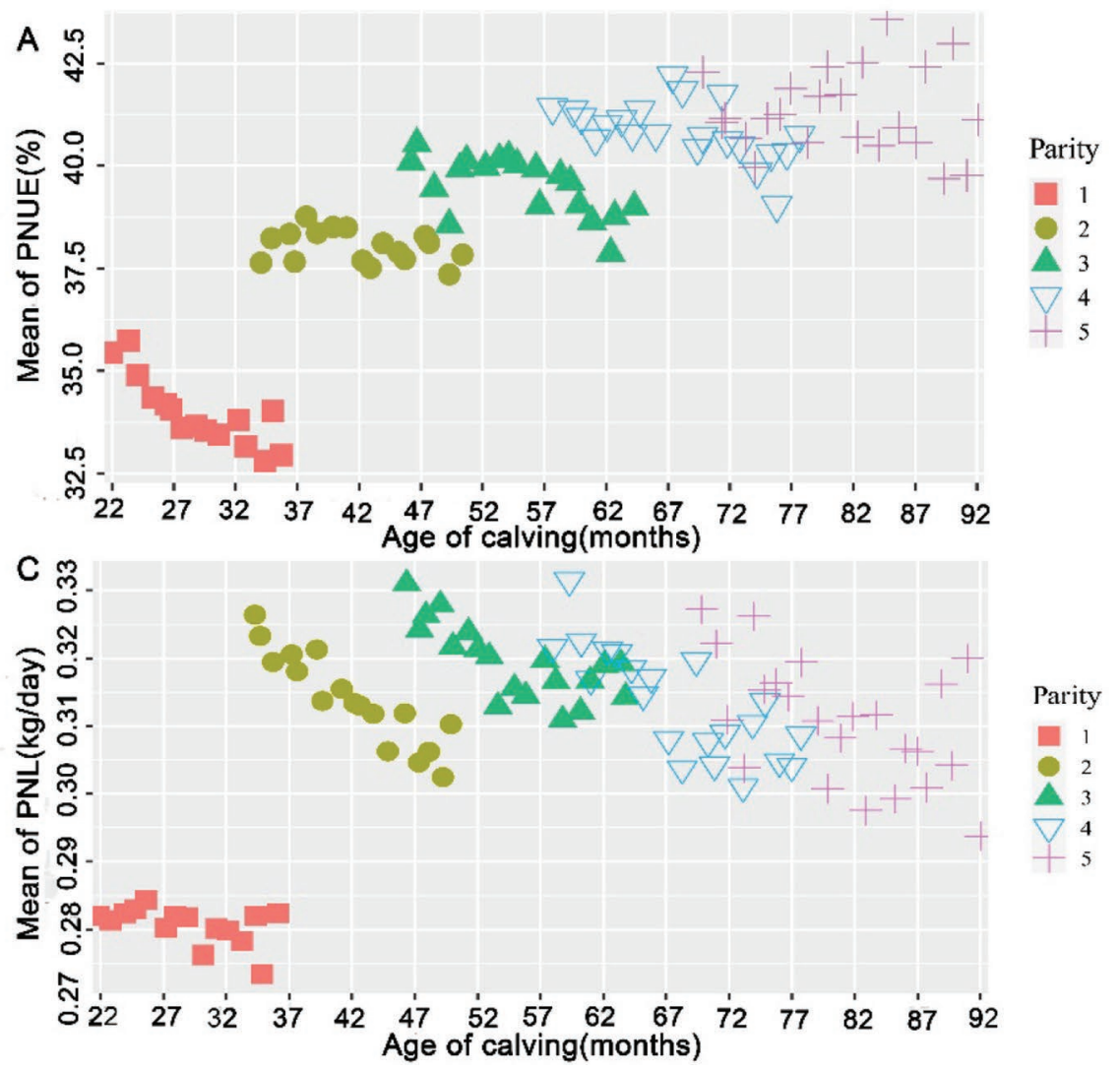

B
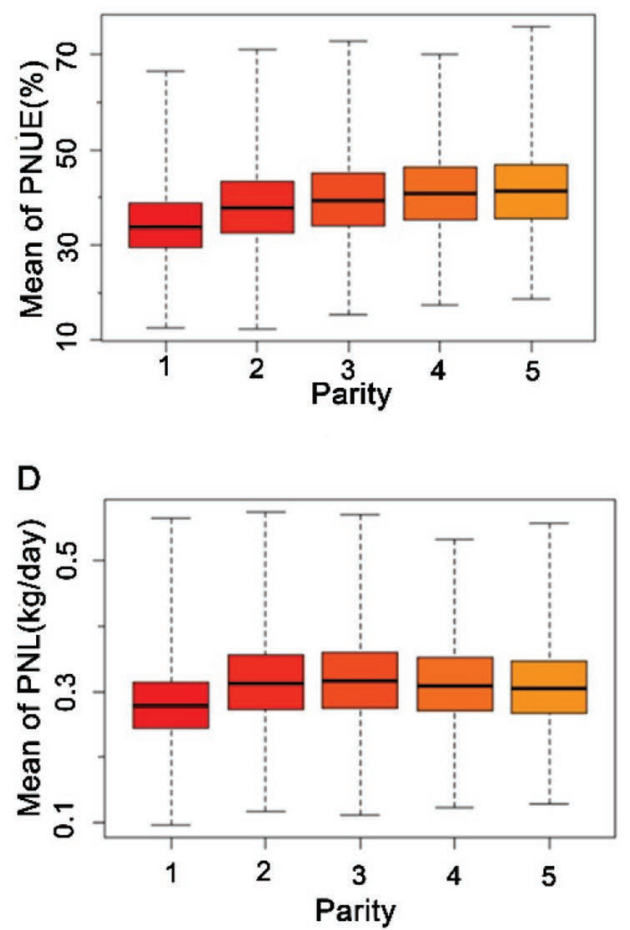

Figure 3. Changes in average predicted $\mathrm{N}$ use efficiency (PNUE) and predicted N losses (PNL) with calving age (A and C) and parity of Holstein cows (B and D).

served means and SD, observations outside 3 SD from the means for each trait were considered as outliers and were not used in the study. For PNUE1, PNL1, PNUE2+, and PNL2+ we eliminated only 40, 161, 69, and 166 records, respectively. This restricted the range of values for PNUE1 and PNUE2+ to between 13.6 and $63.5 \%$, which is inside the values used by Grelet et al. (2020) in the calibration process (individual daily NUE ranging from 9.7 to $81.7 \%$, with an average of $36.9 \%$ and SD of $10.4 \%$ ).

As shown in Figure 3, we found that as the parity (the first 5 parities) increases, the average PNUE gradually increases, and the PNL increases first, before becoming stable and then showing a slight tendency to decrease after parity 3. For PNL within each parity, we found a downward trend with the increase of calving age. All these results suggest that even if cows in higher parities tend to be more efficient (higher PNUE), for PNL later parities compared with the first parity showed higher $\mathrm{N}$ losses. Also, although older calving ages inside a given parity were not good for efficiency in the first parity, older animals inside a given parity showed lower losses. These results supported the idea that although the def- initions of PNUE and PNL may indicate similarities, they do not describe the same biological background.

\section{Variance Components, Heritabilities, and Repeatabilities}

The variance for each component, $\mathrm{h}^{2}$, and repeatability of the 4 traits are shown in Table 1 . The $\mathrm{h}^{2}$ of 4 traits range from 0.115 to 0.144 . Given these intermediate levels of $h^{2}$, which are similar to $h^{2}$ found for SCS, the hypothesis considering PNUE or PNL as traits that could be selected can be defended (Montaldo et al., 2010). Repeatability ranged between 0.395 and 0.550 . It can be seen that the $\mathrm{h}^{2}$ and repeatability of PNUE and PNL increased slightly from the first to later parities and that values for PNUE tended to be higher than for PNL. Because we are the first to report the genetic parameters of PNUE and PNL, no directly comparable literature exists. However, previous studies have used ECPU for protein efficiency (Hayes and Ageeb, 2002; Ariyarathne et al., 2019), so we compare them with our results. Recently, Ariyarathne et al. (2019) estimated the average $\mathrm{h}^{2}$ of ECPU to be 0.16 , which was similar to 
Table 1. Heritability $\left(h^{2}\right)$, repeatability (Rep), additive genetic variance $\left(\sigma_{a}^{2}\right)$, across-parity permanent environment (nongenetic cow) variance $\left(\sigma_{\mathrm{c}}^{2}\right.$; only for second and later lactations), within-parity permanent environment (nongenetic cow $\times$ parity) variance $\left(\sigma_{\mathrm{p}}^{2}\right)$, and residual variance $\left(\sigma_{\mathrm{e}}^{2}\right)$ of the proxies for $\mathrm{N}$ use efficiency $(\%)$ and losses (expressed as dekagram/day) in primiparous $(\mathrm{n}=16,456)$ and multiparous $(\mathrm{n}=29,707)$ Holstein cows

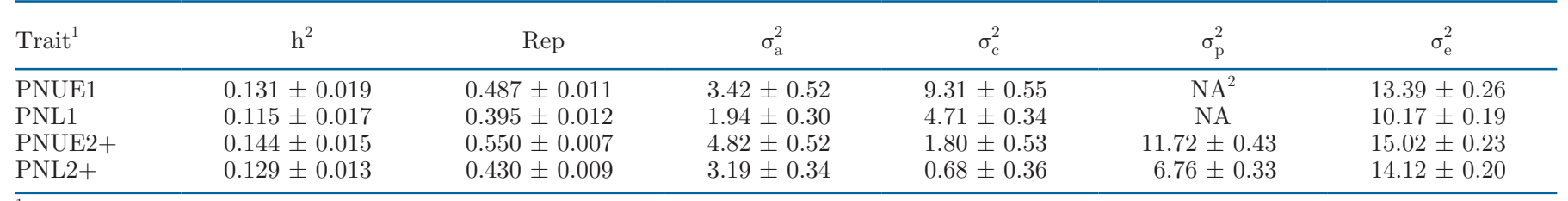

${ }^{1}$ PNUE1 = predicted $\mathrm{N}$ use efficiency in first-parity Holstein cows; PNL1 = predicted $\mathrm{N}$ losses in first-parity Holstein cows; PNUE2 $+=$ predicted $\mathrm{N}$ use efficiency in second- to fifth-parity Holstein cows; PNL2+ = predicted N losses in second- to fifth-parity Holstein cows.

${ }^{2} \mathrm{NA}=$ not applicable.

our results (from 0.12 to 0.14 ), but their mean repeatability tended to be lower ( 0.38 vs. 0.55$)$.

A total of 504 bulls were used in the estimation of approximate genetic correlations. Because Ireland and Belgium are currently importers of a lot of Holstein semen, many important semen-exporting countries were present (e.g., the USA, Canada, Italy, Germany, and France). In the Netherlands, many local bulls are traditionally used, adding to the strong presence of bulls born in this country. The precise distributions, according to the countries of origin and year of birth of the bulls, are shown in Table 2. Breeding values used in this study showed averages and SD for reliability of PNUE1, PNL1, PNUE2+, and PNL2+ that ranged from 0.47 to 0.52 and from 0.14 to 0.16 . The averages and SD of reliability for EBV of all multiple-trait across-country evaluation traits ranged from 0.75 to 0.96 and from 0.03 to 0.14 , respectively.

\section{Genetic and Phenotype Correlations}

As explained previously, even if NUE and NL are somewhat related, they do not represent exactly the same biological background. Therefore, genetic and phenotypic correlations between PNUE and PNL were computed, and the results are reported in Table 3. As expected by their definition, PNUE and PNL showed negative correlations between them. Inside the same trait group, the correlations were positive. The genetic and phenotypic correlation ranged between -0.89 and

Table 2. Distribution of year and country of birth of the bulls used $(\mathrm{n}=504)$

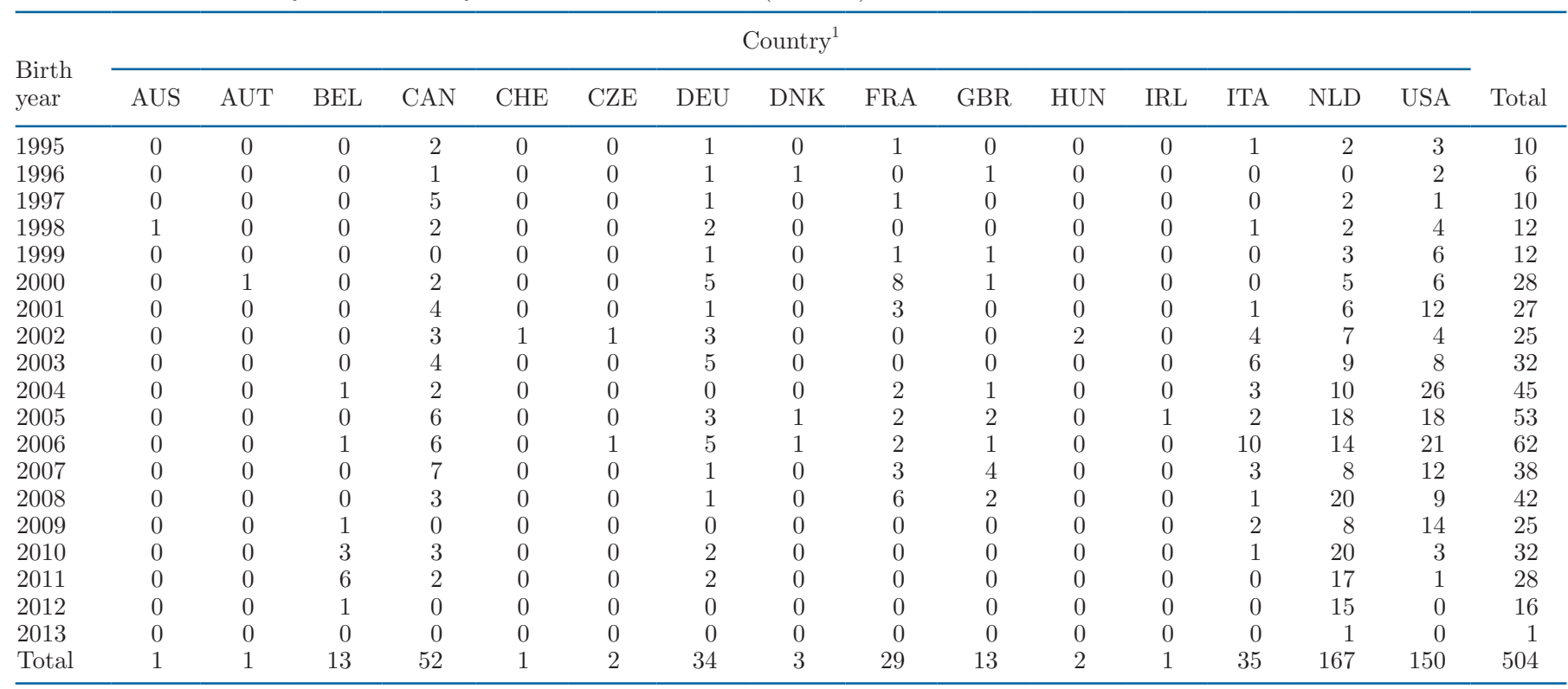

${ }^{1}$ AUS = Australia; AUT = Austria; BEL = Belgium; CAN = Canada; CHE = Switzerland; CZE = Czech Republic; DEU = Germany; DNK $=$ Denmark; FRA = France; GBR = United Kingdom; HUN = Hungary; IRL = Ireland; ITA = Italy; NLD = Netherlands; USA = United States of America. 
Table 3. Genetic correlations (above the diagonal) and phenotype correlations (below the diagonal) among reported $\mathrm{N}$ use efficiency and loss traits in primiparous $(\mathrm{n}=16,456)$ and multiparous $(\mathrm{n}=29,707)$ Holstein cows

\begin{tabular}{|c|c|c|c|c|}
\hline Trait $^{1}$ & PNUE1 & PNL1 & PNUE2+ & PNL2+ \\
\hline PNUE1 & & $-0.89 \pm 0.04$ & $0.68 \pm 0.08$ & $-0.53 \pm 0.08$ \\
\hline PNL1 & $-0.42 \pm 0.01$ & & $-0.63 \pm 0.08$ & $0.72 \pm 0.07$ \\
\hline PNUE2+ & $0.16 \pm 0.01$ & $-0.13 \pm 0.01$ & & $-0.79 \pm 0.04$ \\
\hline PNL2+ & $-0.11 \pm 0.01$ & $0.13 \pm 0.01$ & $-0.45 \pm 0.01$ & \\
\hline
\end{tabular}

${ }^{1}$ PNUE1 = predicted $\mathrm{N}$ use efficiency in first-parity Holstein cows; PNL1 = predicted $\mathrm{N}$ losses in first-parity Holstein cows; PNUE2+ = predicted $\mathrm{N}$ use efficiency in second- to fifth-parity Holstein cows; PNL2+ = predicted $\mathrm{N}$ losses in second- to fifth-parity Holstein cows.

0.72 , and -0.45 and 0.16 , respectively. Additional features appeared. First correlations were, in absolute values, stronger among different traits in the same parity groups. We found that PNUE1 had the largest genetic negative correlation with PNL1 (-0.89) and the lowest with PNL2+ $(-0.53)$. Meanwhile, PNL2+ had the lowest negative phenotypic correlation with PNUE1 $(-0.11)$ and the largest with PNUE2+ $(-0.45)$. This supported the hypothesis that first and later lactations are different traits. For both PNUE traits, even with a very high genetic correlation of 0.68 , the phenotypic correlation between them was as low as 0.16. Similarly, for both PNL traits, the genetic correlation was 0.72 , and the phenotypic correlation between them was as low as 0.13 . Based on these results, we cannot say that PNUE and PNL are genetically similar traits. Each one

Table 4. Approximate genetic correlation ${ }^{1}$ between predicted $\mathrm{N}$ use efficiency and $\mathrm{N}$ loss, and other traits evaluated in bulls ${ }^{2}(\mathrm{n}=504)$

\begin{tabular}{|c|c|c|c|c|c|}
\hline Trait & Milk yield & PNUE1 & PNL1 & PNUE2+ & PNL2+ \\
\hline Milk yield & $\mathrm{NA}^{3}$ & $0.47 \pm 0.06$ & $-0.10 \pm 0.07$ & $0.21 \pm 0.06$ & $0.10 \pm 0.07$ \\
\hline Fat yield & $0.43 \pm 0.04$ & $0.24 \pm 0.06$ & $0.22 \pm 0.07$ & $0.04 \pm 0.07$ & $0.38 \pm 0.06$ \\
\hline \multicolumn{6}{|l|}{ Milk composition } \\
\hline Fat percentage & $-0.58 \pm 0.04$ & $-0.19 \pm 0.08$ & $0.28 \pm 0.07$ & $-0.14 \pm 0.07$ & $0.25 \pm 0.07$ \\
\hline Protein percentage & $-0.43 \pm 0.04$ & $-0.06 \pm 0.08$ & $0.32 \pm 0.07$ & $0.03 \pm 0.07$ & $0.25 \pm 0.07$ \\
\hline Longevity & $-0.05 \pm 0.05$ & $-0.33 \pm 0.08$ & $0.39 \pm 0.06$ & $-0.31 \pm 0.06$ & $0.36 \pm 0.06$ \\
\hline Female fertility & $-0.46 \pm 0.04$ & $-0.44 \pm 0.07$ & $0.41 \pm 0.07$ & $-0.42 \pm 0.06$ & $0.36 \pm 0.06$ \\
\hline $\mathrm{BCS}$ & $-0.05 \pm 0.05$ & $-0.14 \pm 0.07$ & $0.41 \pm 0.07$ & $-0.12 \pm 0.07$ & $0.33 \pm 0.07$ \\
\hline Direct calving ease & $0.20 \pm 0.05$ & $-0.07 \pm 0.07$ & $0.39 \pm 0.07$ & $-0.35 \pm 0.07$ & $0.57 \pm 0.06$ \\
\hline Maternal calving ease & $0.03 \pm 0.06$ & $-0.34 \pm 0.07$ & $0.32 \pm 0.06$ & $-0.36 \pm 0.06$ & $0.31 \pm 0.06$ \\
\hline \multicolumn{6}{|l|}{ Conformation traits } \\
\hline Stature & $-0.09 \pm 0.05$ & $-0.14 \pm 0.08$ & $-0.05 \pm 0.08$ & $-0.14 \pm 0.07$ & $0.00 \pm 0.07$ \\
\hline Rear leg set & $-0.05 \pm 0.04$ & $-0.1 \pm 0.07$ & $-0.03 \pm 0.06$ & $-0.13 \pm 0.06$ & $0.00 \pm 0.06$ \\
\hline Rear leg rear view & $0.02 \pm 0.05$ & $0.06 \pm 0.07$ & $-0.04 \pm 0.07$ & $0.15 \pm 0.06$ & $-0.11 \pm 0.06$ \\
\hline Udder height & $-0.37 \pm 0.04$ & $-0.46 \pm 0.06$ & $0.18 \pm 0.07$ & $-0.36 \pm 0.06$ & $0.12 \pm 0.06$ \\
\hline Udder support & $-0.06 \pm 0.05$ & $-0.08 \pm 0.07$ & $-0.20 \pm 0.07$ & $-0.03 \pm 0.07$ & $-0.18 \pm 0.07$ \\
\hline Fore udder & $-0.29 \pm 0.04$ & $-0.29 \pm 0.07$ & $-0.06 \pm 0.07$ & $-0.11 \pm 0.07$ & $-0.16 \pm 0.07$ \\
\hline Front teat placement & $0.07 \pm 0.04$ & $-0.11 \pm 0.07$ & $0.17 \pm 0.06$ & $-0.12 \pm 0.06$ & $0.12 \pm 0.06$ \\
\hline Teat length & $0.11 \pm 0.04$ & $0.03 \pm 0.06$ & $-0.15 \pm 0.06$ & $-0.03 \pm 0.06$ & $-0.06 \pm 0.06$ \\
\hline Rear udder height & $0.05 \pm 0.05$ & $-0.04 \pm 0.07$ & $-0.21 \pm 0.07$ & $-0.02 \pm 0.07$ & $-0.14 \pm 0.07$ \\
\hline Rear teat placement & $0.02 \pm 0.05$ & $0.06 \pm 0.07$ & $-0.22 \pm 0.06$ & $0.15 \pm 0.06$ & $-0.26 \pm 0.06$ \\
\hline Angularity & $-0.06 \pm 0.04$ & $-0.02 \pm 0.07$ & $-0.32 \pm 0.07$ & $0.02 \pm 0.07$ & $-0.26 \pm 0.07$ \\
\hline Overall feet and leg score & $0.00 \pm 0.05$ & $-0.02 \pm 0.07$ & $0.01 \pm 0.06$ & $0.09 \pm 0.07$ & $-0.07 \pm 0.06$ \\
\hline Overall udder score & $-0.23 \pm 0.05$ & $-0.34 \pm 0.06$ & $-0.01 \pm 0.07$ & $-0.23 \pm 0.06$ & $-0.04 \pm 0.07$ \\
\hline Overall conformation score & $-0.12 \pm 0.05$ & $-0.23 \pm 0.07$ & $-0.07 \pm 0.07$ & $-0.16 \pm 0.07$ & $-0.06 \pm 0.07$ \\
\hline
\end{tabular}

\footnotetext{
${ }^{1}$ Approximate genetic correlations were estimated using the strategy presented by Blanchard et al. (1983).
}

${ }^{2}$ PNUE1 = predicted N use efficiency in first-parity Holstein cows; PNL1 = predicted N losses in first-parity Holstein cows; PNUE2 $+=$ predicted $\mathrm{N}$ use efficiency in second- to fifth-parity Holstein cows; PNL2+ = predicted N losses in second- to fifth-parity Holstein cows.

${ }^{3} \mathrm{NA}=$ not applicable. 
is also slightly genetically different, comparing first and later lactations. Phenotypically, large differences also appeared among all studied traits.

\section{Approximate Genetic Correlations}

Results obtained so far indicate that the PNUE and PNL traits show potential for genetic improvement; however, it is also necessary to assess how these novel traits correlate to other traits already under selection in most Holstein populations. Table 4 describes approximate genetic correlations between PNUE, PNL, and 30 traits of interest using Blanchard's approach by EBV. Estimating genetic relationships among traits under selection may reflect genetic trends for selected traits instead of real genetic correlations. Therefore, and to evaluate the suitability of this approximate approach, we calculated the approximate genetic correlations of milk yield with other traits using the same approach (Table 4). Results showed that the approximate genetic correlations between milk yield and other traits were similar to genetic correlations found in other studies (Campos et al., 2015; Zhao et al., 2015). These results supported our hypothesis that the use of Blanchard's approach in our context can yield reasonable approximate correlations.

As shown in Table 4, the approximate genetic correlations of PNUE and yield traits (milk, fat, and protein) ranged from 0.04 to 0.47 . In particular, milk and protein yields showed relevant positive correlations, indicating that their improvement may have increased NUE in the past, as expressed by PNUE. Milk fat percentage showed negative correlations $(-0.19$ and -0.14$)$, and protein percentage nearly zero correlations, indicating that the correlations between yields and PNUE might essentially be due to the high correlations with milk yield. Results for PNL have to be considered always bearing in mind that lower PNL values are associated with better efficiency. When considering PNL, current selection favoring higher fat and protein yields, as in the Walloon selection index V€G, would increase PNL and therefore decrease $\mathrm{N}$ efficiency. Based on these results we can again argue that PNUE and PNL seem to be genetically very different traits.

As explained previously, efficiency traits may be in opposition to health and other functional traits. As shown in Table 4, more favorable PNUE genetically decreased other important traits such as udder health, female fertility, longevity, and calving ease (direct and maternal). The effect on BCS was less clear. For most traits, the effects were as expected because of their links to milk yield, except for the effects on longevity and calving ease, which were clearly stronger than expected, indicating a specific direct link. To clarify why such strong correlations were observed for calving ease, approximate genetic correlations were computed between calving ease traits and all other traits (detailed results not shown). A common rationale is that sires transmitting bigger size also generate more direct calving difficulties. This was only partially confirmed, as correlations between direct calving ease and body development traits were only between -0.15 and -0.31 . For maternal calving ease, with the exception of stature (0.22), correlations were very close to zero. However, for direct calving ease correlations with health and other functional traits were all positive and rather strong between 0.28 for udder health and 0.53 for longevity. For maternal calving ease, the corresponding correlations were all positive but lower. Except for BCS, with a correlation that was very close to zero, the correlations ranged from 0.13 for udder health to 0.27 for longevity. This finding might indicate that animals that are more efficient are unfortunately less robust and show lower longevity. Findings also indicate that all health and other functional traits are similarly affected, including calving ease traits. The results for PNL were as expected, nearly equivalent to those for PNUE except for BCS, where we observed a much stronger negative association with $\mathrm{N}$ efficiency, expressed through PNL. This could indicate that selecting for direct reduced N loss does not only affect $\mathrm{N}$ excreted to the environment but also leads to less $\mathrm{N}$ available to maintain body condition, probably through reduced $\mathrm{N}$ intake. All our results rather strongly support the hypothesis that feed efficiency traits, here $\mathrm{N}$, are in opposition to health and other functional traits.

For conformation traits, correlations were only reasonably high between udder traits, or udder-related traits and PNUE. By comparing with the correlations of these traits and milk yield, it appeared that, with a high likelihood, the observed correlations are due to the strong links between milk yield and PNUE. It is difficult to interpret other correlations, most being very small. Future studies could confirm some indications, such as the negative effect on stature, which may be part of the reduction in the availability of $\mathrm{N}$ for body growth (Figure 1). In addition, cattle with large stature consume a lot of energy for maintenance. For PNL the results were rather diverse, with a less strong association with udder traits. As expected by the results from BCS, animals that were genetically more efficient for $\mathrm{N}$, expressed through lower PNL values, tended to be more angular.

In short, increasing PNUE seems to have a favorable selection response for yield traits, but not favorable ones for udder health, longevity, and reproduction. According to the definition of PNL, lower PNL may be beneficial and reduce environmental pollution. By 
correcting for the desired direction of selection (i.e., lower PNL values), most traits (19 traits) showed the same trend in their genetic relationship with PNL as with PNUE (Table 4). However, even if most correlations made perfect sense, the biological links are not always clear. Moreover, we should not forget that we studied here the proxies (PNUE and PNL) and not the underlying direct traits NUE and NL. The same situation (i.e., working on proxies based on imperfect predictions and not the direct traits) has appeared in many other studies (e.g., Zaalberg et al., 2020) that estimated approximate genetic correlation between the MIR predicted trait and other traits.

However, a feature of MIR-based predictions is that, when prediction equations with improved prediction accuracy become available, we can easily recalculate improved proxy phenotypes PNUE and PNL. Because we cannot expect direct NUE or NL to become available on a large scale, we have to rely on the use of PNUE or PNL to select cows. This means that NUE or NL could become part of the breeding goal that contains the traits we want to improve. The traits PNUE or PNL would then be part of the index traits. This situation is very similar to the current selection against mastitis: the breeding goal trait is incidence of mastitis, but the index trait is very often SCS. Furthermore, this study showed several other directions where future research is required. First, the well-known issue of using DMI versus residual feed intake parallels our situation, where the components of NUE and NL are the N content of DMI and the $\mathrm{N}$ content of protein yield, the difference between those (i.e., NL) mirroring residual feed intake. All of this warrants additional research. Second, the design of this study did not allow the investigation of the relationship between PNUE (PNL) and other direct measures of $\mathrm{N}$ (e.g., milk urea nitrogen) that might be easier to comprehend.

\section{CONCLUSIONS}

In summary, our study showed first estimates of genetic parameters for PNUE and PNL traits and approximate genetic correlations between PNUE, PNL, and other traits currently reported by Interbull. The estimated heritability of PNUE and PNL ranged from 0.12 to 0.14 , and the repeatability values ranged from 0.40 to 0.55 , respectively. These results seem to suggest that selection of $\mathrm{N}$ efficiency-related traits is possible. Our results also showed that $\mathrm{N}$ efficiency traits could be in opposition to health and other functional traits. It should be noted that the data we studied were only from the early lactation (the first 50 DIM). Finally, if validated for their link to $\mathrm{N}$ excretion, PNUE and PNL could also be used to aid $\mathrm{N}$ management in dairy farms to improve farmers' profits as well as to reduce environmental pollution.

\section{ACKNOWLEDGMENTS}

The China Scholarship Council (Beijing) is acknowledged for funding the $\mathrm{PhD}$ project of Yansen Chen. The GplusE project has received funding from the European Union's Seventh Framework Programme (Brussels, Belgium) for research, technological development, and demonstration, under grant agreement no. 613689. The views expressed in this publication are the sole responsibility of the authors and do not necessarily reflect the views of the European Commission. The authors thank the 5 organizations and universities Royal Veterinary College (London, UK), Walloon Breeders Association (Ciney, Belgium), Irish Cattle Breeding Federation Society Limited (Bandon, Ireland), Huazhong Agricultural University (Wuhan, China), and CRV (Arnhem, the Netherlands) for collecting and providing the MIR data used here. The authors acknowledge the support of the Walloon Government (Service Public de Wallonie - Direction Générale Opérationnelle Agriculture, Ressources Naturelles et Environnement, SPW-DGARNE; Namur, Belgium) and the use of the computation resources of the University of Liège - Gembloux AgroBio Tech (Liège, Belgium) provided by the technical platform Calcul et Modélisation Informatique (CAMI) of the TERRA Teaching and Research Centre, partly supported by the Fonds de la Recherche Scientifique - FNRS under grants no. T.0095.19 (PDR "DEEPSELECT") and J.0174.18 (CDR "PREDICT-2"). The authors have not stated any conflicts of interest.

\section{REFERENCES}

Adenuga, A. H., J. Davis, G. Hutchinson, T. Donnellan, and M. Patton. 2019. Environmental efficiency and pollution costs of nitrogen surplus in dairy farms: A parametric hyperbolic technology distance function approach. Environ. Resour. Econ. 74:1273-1298. https://doi.org/10.1007/s10640-019-00367-2.

Ariyarathne, H., M. Correa-Luna, H. T. Blair, D. J. Garrick, and N. Lopez-Villalobos. 2019. Estimation of heritabilities for milk urea and efficiency of crude protein utilization by day of lactation in a New Zealand dairy cow herd. N. Z. J. Anim. Sci. Prod. 79:183-187.

Blanchard, P. J., R. W. Everett, and S. R. Searle. 1983. Estimation of genetic trends and correlations for Jersey cattle. J. Dairy Sci. 66:1947-1954. https://doi.org/10.3168/jds.S0022-0302(83)82033 -5 .

Campos, R. V., J. A. Cobuci, E. L. Kern, C. N. Costa, and C. M. McManus. 2015. Genetic parameters for linear type traits and milk, fat, and protein production in Holstein cows in Brazil. Asian-Australas. J. Anim. Sci. 28:476-484. https://doi.org/10.5713/ajas.14 .0288 .

Cantalapiedra-Hijar, G., R. J. Dewhurst, L. Cheng, A. R. J. Cabrita A. J. M. Fonseca, P. Nozière, D. Makowski, H. Fouillet, and I. Ortigues-Marty. 2018. Nitrogen isotopic fractionation as a biomarker for nitrogen use efficiency in ruminants: A meta-analysis. Animal 12:1827-1837. https://doi.org/10.1017/S1751731117003391. 
Cantalapiedra-Hijar, G., H. Fouillet, J. F. Huneau, A. Fanchone, M. Doreau, P. Nozière, and I. Ortigues-Marty. 2016. Relationship between efficiency of nitrogen utilization and isotopic nitrogen fractionation in dairy cows: Contribution of digestion v. metabolism? Animal 10:221-229. https://doi.org/10.1017/S1751731115002025.

Canty A., and B. Ripley. 2019. boot: Bootstrap R (S-Plus) Functions. $\mathrm{R}$ package version 1.3-24. R Foundation for Statistical Computing, Vienna, Austria. Accessed May 19, 2020. https://CRAN.R-project . org $/$ package $=$ boot.

Castillo, A. R., E. Kebreab, D. E. Beever, J. H. Barbi, J. D. Sutton, H. C. Kirby, and J. France. 2001. The effect of protein supplementation on nitrogen utilization in lactating dairy cows fed grass silage diets. J. Anim. Sci. 79:247-253. https://doi.org/10.2527/ 2001.791247x.

Dowle, M., and A. Srinivasan. (2019). data.table: Extension of 'data. frame.' R package version 1.12.8. Accessed May 19, 2020. https:// CRAN.R-project.org/package $=$ data.table.

Gengler, N., M. Hostens, and E. Gplus. Consortium. 2018. How fast can we change resilience and efficiency through breeding and management? Accessed Jan. 21, 2021. https://orbi.uliege.be/ bitstream/2268/234176/2/S21_03_Gengler.pdf.

Gengler, N., H. Soyeurt, F. Dehareng, C. Bastin, F. Colinet, H. Hammami, M. L. Vanrobays, A. Lainé, S. Vanderick, C. Grelet, A. Vanlierde, E. Froidmont, and P. Dardenne. 2016. Capitalizing on fine milk composition for breeding and management of dairy cows. J. Dairy Sci. 99:4071-4079. https://doi.org/10.3168/jds.2015-10140.

Grelet, C., J. A. Fernández Pierna, P. Dardenne, V. Baeten, and F. Dehareng. 2015. Standardization of milk mid-infrared spectra from a European dairy network. J. Dairy Sci. 98:2150-2160. https://doi .org/10.3168/jds.2014-8764.

Grelet, C., E. Froidmont, L. Foldager, M. Salavati, M. Hostens, C. P. Ferris, K. L. Ingvartsen, M. A. Crowe, M. T. Sorensen, J. A. Fernandez Pierna, A. Vanlierde, N. GenglerGplusE Consortium, and F. Dehareng. 2020. Potential of milk mid-infrared spectra to predict nitrogen use efficiency of individual dairy cows in early lactation. J. Dairy Sci. 103:4435-4445. https://doi.org/10.3168/ jds.2019-17910.

Hayes, J. F., and A. G. A. Ageeb. 2002. Genetic parameters for feed efficiency in Holsteins. Proc. 7th World Congress on Genetics Applied to Livestock Production, Montpellier, France. Accessed Jan. 21, 2021. http://www.wcgalp.org/system/files/proceedings/2002/ genetic-parameters-feed-efficiency-holsteins.pdf.

Lopez-Villalobos, N., M. Correa-Luna, J. L. Burke, N. W. Sneddon, M. M. Schutz, D. J. Donaghy, and P. D. Kemp. 2018. Genetic parameters for milk urea concentration and milk traits in New Zealand grazing dairy cattle. N. Z. J. Anim. Sci. Prod. 78:56-61.

Meyer, K., and D. Houle. 2013. Sampling based approximation of confidence intervals for functions of genetic covariance matrices. Proc. Assoc. Advmt. Anim. Breed. Genet. 20:523-526.

Misztal, I., S. Tsuruta, D. A. L. Lourenco, Y. Masuda, I. Aguilar, A. Legarra, and Z. Vitezica. 2018. Manual for BLUPF90 family programs. University of Georgia. Accessed May 19, 2020. http://nce .ads.uga.edu/wiki/doku.php?id=documentation.
Montaldo, H. H., H. Castillo-Juárez, M. Valencia-Posadas, E. G. Cienfuegos-Rivas, and F. J. Ruiz-López. 2010. Genetic and environmental parameters for milk production, udder health, and fertility traits in Mexican Holstein cows. J. Dairy Sci. 93:2168-2175. https: //doi.org/10.3168/jds.2009-2050.

Nasrollahi, S. M., P. Nozière, R. J. Dewhurst, C. Chantelauze, L. Cheng, E. Froidmont, C. Martin, and G. Cantalapiedra-Hijar. 2019. Natural $15 \mathrm{~N}$ abundances in plasma and urea- $\mathrm{N}$ concentration in milk as biomarkers of urinary $\mathrm{N}$ excretion in dairy cows: a meta-analysis. EAAP Scientific Series. 138:267-268. https://doi .org/10.3920/978-90-8686-891-9_66.

Phuong, H. N., N. C. Friggens, I. J. M. de Boer, and P. Schmidely. 2013. Factors affecting energy and nitrogen efficiency of dairy cows: A meta-analysis. J. Dairy Sci. 96:7245-7259. https://doi .org $/ 10.3168 / \mathrm{jds} .2013-6977$.

R Core Team. 2020. R: A language and environment for statistical computing. R Foundation for Statistical Computing, Vienna, Austria. Accessed May 19, 2020. https://www.R-project.org/.

Vanlierde, A., M.-L. Vanrobays, F. Dehareng, E. Froidmont, H. Soyeurt, S. McParland, E. Lewis, M. H. Deighton, F. Grandl, M. Kreuzer, B. Gredler, P. Dardenne, and N. Gengler. 2015. Hot topic: Innovative lactation-stage-dependent prediction of methane emissions from milk mid-infrared spectra. J. Dairy Sci. 98:57405747. https://doi.org/10.3168/jds.2014-8436.

Wheadon, N. M., M. McGee, G. R. Edwards, and R. J. Dewhurst. 2014. Plasma nitrogen isotopic fractionation and feed efficiency in growing beef heifers. Br. J. Nutr. 111:1705-1711. https://doi.org/ 10.1017/S0007114513004078.

Whitfield, R. G., M. E. Gerger, and R. L. Sharp. 1987. Near-infrared spectrum qualification via Mahalanobis distance determination. Appl. Spectrosc. 41:1204-1213. https://doi.org/10.1366/ 0003702874447572.

Wickham, H. 2016. Ggplot2: Elegant Graphics for Data Analysis. Springer-Verlag, New York, NY.

Zaalberg, R. M., A. J. Buitenhuis, U. K. Sundekilde, N. A. Poulsen, and H. Bovenhuis. 2020. Genetic analysis of orotic acid predicted with Fourier transform infrared milk spectra. J. Dairy Sci. 103:3334-3348. https://doi.org/10.3168/jds.2018-16057.

Zhao, F. P., G. Guo, Y. C. Wang, X. Y. Guo, Y. Zhang, and L. X. Du. 2015. Genetic parameters for somatic cell score and production traits in the first three lactations of Chinese Holstein cows. J. Integr. Agric. 14:125-130. https://doi.org/10.1016/S2095 -3119(14)60758-9.

\section{ORCIDS}

Y. Chen (®) https://orcid.org/0000-0002-8593-4384

S. Vanderick $\odot$ https://orcid.org/0000-0003-4556-4718

R. R. Mota @ https://orcid.org/0000-0003-0566-3236

C. Grelet ๑ https://orcid.org/0000-0003-3313-485X

N. Gengler ๑ https://orcid.org/0000-0002-5981-5509 